\title{
The Evaluation of the Influence of Mentality on Modernization Processes in Modern Russia
}

Marina Cherkasova

Svetlana Bayurova

Vladimir Khamov

Vadim Cherkasov

Branch of the Russian State Social University in Kamensk-Shakhtinsky

Email: kamensk@rgsu.net

\section{Doi:10.5901/mjss.2015.v6n3s4p109}

\section{Abstract}

\begin{abstract}
Today, high is scientific and practical interest to the study of conditions of formation and development of civil society in Russia. Construction of a civil society is seen today as the main precondition of ensuring the personal safety of citizens, especially the rights of the individual, the socio-economic security of the individual, overcoming of political exclusion. The researchers see the mentality of the people as an important precondition for the formation and development of civil society in Russia. To identify and study relevant characteristics of the Russian national character for the formation and development of civil society, it is necessary to apply complex of knowledge (philosophical, anthropological, cultural, psychological, sociological, political). The study of mental values and ideals of the Russian society, reflecting the civil qualities of the Russian people will help to find the answer to indispensable question of up-to-dateness: "Will Russia be saved as an independent, unified and democratic country?. Knowing the characteristics of Russian society, it is possible to form civil society, using all the positive elements of ethnic mentality of the titular peoples of different regions of the country. The most promising mental qualities can become the basis for the purposeful formation of new system of values and norms allowing to ensure the success of socio-economic and political transformation. Without regard to the content of mental representations as the values structure cannot be ensured the adequacy of the reforms.
\end{abstract}

Keywords: mentality, civil society, Russian society, mental representations, value structure.

\section{Introduction}

At the present time in Russia just another round of modernization is observed, which puts in the forefront the tasks of updating and reconstruction of social reality. Using the available historical experience and the achievements of modern science, today Russia has a unique opportunity to transition from the method of "tests and errors" to develop a scientifically based concept of transforming the country. Contemporary modernization processes should be aimed at achieving social well-being of man and society. And for that at formulating public policies, in the first place, it is necessary to consider the cultural and historical traditions, mentality, character, social relationships, limited opportunities for export of foreign experience in Russia and the uniqueness of the Russian state.

At study of the influence of mentality on the processes of modernization in modern Russia, on the formation of civil society we cannot disagree with V. F. Svetov, who literally writes the following: "There is an underestimation of the role of mentality as a determining factor and criterion for the selection of optimal variants of reforms... The errors of liberal reformers are largely connected with the misunderstanding of the essence of the relationship of consciousness and Genesis, according to which mental spiritual factor played a supporting role, and ideological reformers rely on not mental levels of Russian civilization, but on the individual elements of Western science. The study of Russian mentality allows the consideration of the archetypes of folk consciousness and not only to legitimize, but to stimulate the modernization processes in Russia." (Covetov, 2007, p. 4)

\section{Literature Review}

The use of the category of "mentality" allows to carry out more accurate analysis of the current situation in the field of 
social, economic and political changes in the lives of Russians, living on different "floors" of a public building.

So, what is included in the concept of "mentality"? According to the definition of a connoisseur of modern concepts of mentality A. Y. Gurevich - "this is the prism through which people and society perceive the world". R. A. Khanakhu defines mentality as "specific, culturally defined and socially reinforced patterns of behavior, significantly distinguishing one patterns of behavior and thinking from another; a system of hierarchically interdependent priorities and values, able to transform into a cultural-psychological and cultural-behavioral automatisms". (Khanakhu, 1997, p. 66)

E. A. Andreeva on the basis of a generalized "portrait" of mentality gives the following definition: "Mentality is a socio - psychological attitudes, automatisms and habits of mind, ways of seeing, representing people belonging to a particular socio-cultural, ethnic community, their "matrix perception", "cultural codes". It has to do with spiritual values of the community, is reflecting in the behavior of people, in sign systems of culture, in ideas and beliefs; involves elements, unconscious carriers of this mentality. (Andreeva, 2005, http://sib-subethnos.narod.ru/p2005/andreeval.htm, p. 28).

The structuring of mentality is directly connected with the concept of nature of mentality. So G. N. Drepa, A. N. and E. J. Dmitrievys suggest that the mentality stands in 3 modalities:

- $\quad$ in the form of a flexible, movable and stable elements of the structure of the human psyche;

- $\quad$ types of relations between person-person, person-group, person-society;

- $\quad$ as the results of this interaction and follow-up activity, forming the so-called mental environment.

Researchers G. O. Usenko, A. A. Pelipenko, I. G. Yakovenko offer their models of structure of mentality.

Understanding whole complexity of defining the mentality, researcher V. V. Kozlovsky presents the mentality structure, consisting of seven blocks:

1) meanings system;

2) values;

3) typical intellectual and affective reactions;

4) codes of culture;

5) the forms of adopted and rejected behavior;

6) social presentations;

7) the system of susceptibility.

I. V. Mostovaya and A. P. Skorik, in their work "The archetypes and the benchmarks of the Russian mentality", propose the following structure of mentality:

1) Particular culture.

2) Spiritual selfbeing.

3) Social response.

4) Metasocial level.

A. E. Gramnicki identifies seven distinctive features of the Russian mentality:

- moral - ethical orientation in contrast to the pragmatic orientation of the West;

- maintaining of good relations, "the truth", "the correctness" of the achieved results and not getting of the end result as in the West;

- enforcement, necessity of order, and not the belief as in the West;

- the predominance of foreign economic goals, and not the belief as in the West;

- antipositional relationships of partners, and not positional behavior as in the West;

- internal motive of the majority of population: "Let he does not have much than I";

- the dominance of the belief in the necessity of a centralized, single solution of problems.

However, to consider this characteristic absolutely true characteristic of the Russian mentality is unlikely to be true. As the principal fundamental in the Russian mentality, is spirituality, focus on the future as opposed to a grounded pragmatism, immediacy. Some features of the Russian mentality are associated with the so-called "effect of the facade".

In the definition of the essence of the phenomenon of mentality, forming schools in mentality has developed their approaches in the area of methodology.

In determining the nature of mentality polar methodological principles and research programs are observed. Some scientists build their assumptions and lead proofs on the understanding of the mentality as a phenomenon of group consciousness and of the psyche and deny the existence of the individual mentality, others see in individuality the only carrier of mentality. Thus most researchers generally do not use information of the natural sciences in this area of knowledge.

We in our study give the following author's definition of mentality. Mentality is a biologically specified, socially and culturally embodied features of variants of thinking and actions of the individual, groups, in General, of a particular society, which are able to accumulate and be transferred into the sphere of the subconscious, performing the further 
function of reflexes.

In addition, in our opinion, the mentality as the quality of something or someone does not have its own independent existence. The ways of the study of the influence of mentality on modernization process in contemporary Russia are very diverse.

We choose the path of assessing the impact of mentality on modernization processes at different levels (mega-, macro - and micro-) since we assume that the impact at different levels will be different. In general, all three levels will create a quite reasonable picture of such influence.

The global level of influence of mentality on the processes of modernization in modern Russia is difficult to fix. But at this level "the difficulties of the present stage of modernization of Russian society attach to the issue of conformity of the Russian mentality implementing by socio-economic and socio-political innovations especially the topicality" (Petrushenko, 2005, pages 75-76).

Taking into account the multi-ethnic and multi-ethnicity and multi-religious reality of Russia in the past and present, we cannot speak about national Russian mentality, but millennial cohabitation and the Genesis of many of the peoples of Russia have formed not only common socio-cultural features, common features of their spiritual life, but especially, specific ethno-national mental structures that in the history of Russia and the life of its different peoples play an ambivalent role.

The Russian mentality has a number of features that distinguish it not only from Western European mentality but from mentality of other Slavic peoples. And the events of the "orange" revolution in Ukraine are direct confirmation. "In other words," says T. K. Petrushenko, - Russian national mentality at its best in the future can serve as a conductor of various kinds of positive innovations in social time and space of the Russian society".

In this context, the context of estimating of the lines of influence of mentality on the processes of modernization in contemporary Russia at the civilized level, some measures of the subjective nature of the measures that can act as a kind program are possible:

- the study of contents and the forms of mentality of different stages at different historical stages of their existence;

- the definition of natural-geographical, economic, social, political and spiritual conditions and factors that would contribute to the emergence of this particular set of mental characteristics of nations and nationalities ;

- correction of mentality with the aim of achieving harmonization of joint life of societies;

- prediction of the effects of political mentality of different social groups on the effectiveness of social progress.

Genuine social progress should include the expanded reproduction of the past humanistic positive experience, and the nature of the modernization of social changes needs to dominate the revolutionary-reformist. Therefore, a positive modernization of Russian society will be considered only in the case when the social conditions as a result of the reforms will be reproduced and strengthened adequately to human nature.

In modern society, in the context of globalization a special place occupy geographically regional reforms. Each region has its own characteristics of natural conditions prevailing cultural structure of interactions, the social nature of the community and the individual. The modern researcher R. Kh. Simonyan notes that "in such regions, the population is of a certain integrity, characterized by developed over centuries special form of symbiosis with nature, specific types of selfsufficiency, common behavioral traits that emerged in the process of adaptation of people to the natural and socio-cultural environment..." (Simonyan, 2012, p. 18).

The peculiarity to think and feel, a kind of picture of the world and the logic of everyday life are caused by the mentality.

The problem of territorial-regional mentality is increasing due to globalization, when regionalization is becoming one of the trends of modern development, where a decisive role is played by the regional structure. Regionalism is characteristic not only for Russia but also for other countries. Actualization of mentality is one of the ways of the system of knowledge of territorial communities and search of subjectively-anthropological factors of the development of territories.

Speaking about the territorial-regional mentality and its influence on the processes of modernization in Russia of the XXI century is necessary to note that it manifests itself most clearly in the customs. The custom is born deep in the social matter of society, the people's life and most of all reflects the fundamental interests of the ethnic group. The mental characteristics of the region are not only in the basic customs, they are found in the situational behavior of the population.

Thus, in the initial period of the revival of the Cossacks by the Russian sociological service "Monitoring" a sociological survey, revealing the attitude of the Cossack and non-Cossack population to the role of Cossack organizations in the system of local government was conducted. Distribution of answers to the question "Do you support the idea of establishing in the Rostov region of Cossack self-government in which the chief executive is the ataman of the 
don Cossacks?" was the following: support the idea of the Cossack - $50.9 \%$ of and $15.2 \%$ of non-Cossack population; it was difficult to answer for $24,0 \%$ of Cossack and $20.5 \%$ of non-Cossack population; other groups did not support this idea. (Modern don Cossacks, 1992, p. 16).

This line of research was continued by $\mathrm{O}$. N. Sysoeva. According to a survey conducted by her, the population's attitude to the Cossack self-government is changing. The question concerning the definition of the aspects of the interaction of the Cossack communities and local governments was given in an open form, which allowed to determine the opinion of the population about the priority directions of activity of Cossack organizations. Among the Cossack population in the order were noted the following preferred areas of activity of Cossack societies: upbringing and education of youth - $90.5 \%$, cultural activities - $85,5 \%$, the activity of the Cossack brigades - $80,1 \%$, military service, $70.3 \%$, protection of nature reserves and wildlife refuges $-51,4 \%$, protection of horticultural plots, partnerships, farms, agricultural land $-38.6 \%$, the protection of important facilities in the area - $13.5 \%$; social protection of the population - 9.5\%, the agricultural activity $-4.3 \%$. The responses of non-Cossack population have about the same dynamics. (Sysoeva, 2007, p. 37)

In the context of reasoning about the impact of political mentality on modernization processes in contemporary Russia, at the macro-level cannot avoid the family, as it played a crucial role in the transmission of mental attitudes and values.

Thus, the study of E. M. Zakharova showed that "the historical memory of the modern family, in spite of spreading recently opinion, is fairly deep, though not in all cases. The majority of respondents (64\%), although fragmentary, are guided in their ancestry for 3-6 generations, of which $58.7 \%$ remember about ancestors in 3-4 generations, 6\% to 5-6 generations, and 2.3\% since ancient times. If we take the average interval of time of life of generations in 30-40 years, it turns out that the depth of the historical memory of the respondents ranges from 100-120 200-250 years. However, the remaining third of respondents keep in memory their ancestry only to the 2nd generation." (Zakharova, 2005, pages. 124125)

It is clear that in terms of primary socialization, provided by the family, namely from the depths of historical memory depends on the degree and quality of family influence on the formation of civil and patriotic value orientations of the younger generations.

E. M. Zakharova shows that with the deepening of historical memory in the family a sense of the young man himself as a citizen is strengthening (from $50 \%$ in families where it is known only about the parents, to $81 \%$ in families leading their ancestry from ancient times); pride of Russian citizenship; a sense of spiritual kinship with Russia. Moreover, young people from families who keep the memory of ancestors, increasingly recognize the new state as successful and are ready to protect it and to contribute fully to its development.

Namely for the reason that mental characteristics are reproduced at the stage of primary socialization in the family, every nation has its own mentality, and, in this sense, regional (ethno-national) mentality is the attribute of every nation. The mentality can not be changed in a short period of time, especially to appear or disappear, as it appears and disappears only with the ethnos.

Characterizing the degree of influence of mentality on political modernization processes on mega-level, such a large group of the population, as the Russians can not be ignored, drawing attention to the feature of Russian mentality, which is associated with unity-community-collectivism. S. I. Duca notes that "the Russians do not seek and has never seeked to individualism, freedom from social ties and obligations, to freedom from the state and public order. Russian people traditionally supports them, he readily creates and reinforces social hierarchy, is committed to creating a strong state". And if to take into account that the mentality changes very slowly and direct access to it is limited (if not prohibited), the mentality can be viewed in two ways:

1) mentality as a steady state in which there is a selection (breeding) of modernization projects;

2) mentality as a restraining factor of economic, political, social and spiritual changes.

Besides the consideration of the influence of mentality on political modernization at the micro-level is complicated by the fact that modernization criteria included mainly economic, political or social settings, and this circumstance greatly complicates the vision of that connection.

However, there are works in which at the analysis of processes of modernization nevertheless is singled out microlevel, and it is denoted differently. In some cases, authors write and talk about "personal syndrome", others mention "modern mentality" (R. Bell), in the third we are talking about the "modern man" (A. Inkeles) in the period of modernization.

So S. A. Efirov believes that the Soviet people were characterized by high self-esteem. In his view, the Soviet people (of which has grown a large part of Russia) was inherent in the social and national "narcissism" - i.e., the admiration of own system or country, national and cultural traditions as opposed to other countries, societies, cultures, 
minorities. After 1917, C. A. Efirov writes "social narcissism for some time been in the form of cosmopolitic-messianic utopianism based on a fanatical belief in the possession of the universal recipe of "salvation" of mankind and sharply hostile to the ideas of pochvennichestvo and patriotism. Then, increasingly, he began to appose, to intertwine, and sometimes to be replaced (while maintaining a significant portion of the former phraseology) by a more traditional form, imperial-russocentric". (Efirov, 1989, p. 28, 46).

I. M. Popova gives completely opposite personal characteristics of the self-assessment. She believes that we had artificially low national self-esteem. Literally, she writes the following: "But, only getting into the field of view in its "native form", "simple Soviet man" became the object of severe criticism and supercilious contempt, resulting in nicknamescategories: "sovok", "homo Soveticus", "copses", etc. And further also she : "In the post-Soviet period, when our contacts with representatives of "Western civilization" should become closer, many of us licked "wounds", unexpectedly discover that a brilliantly white smiles are not a sign of hospitality, and a hugs are not a testimony of affection. On the other hand, we are beginning, finally, to appreciate that, what rapidly began to lose: unselfishness and sincerity, our "primitive" simplicity". (Popova, 2000, p. 31, 33).

Summing up the results of consideration of the influence of mentality on the processes of modernization in contemporary Russia at the macro level, it should be stated that the regional mental characteristics are found not only in the basic customs, but in the situational behavior of the population, as well as in the language. These mental characteristics are very stable, and they distinguish the majority of representatives of one ethnic (regional) entities from another. It should be emphasized that the mentality has a huge resistance to external influences, historical shocks, to the painful economic and social transformations and it is imperative to keep in mind when organizing and conducting national political modernization projects.

Against the civilization characteristics with their global temporal and spatial scales the activity of each individual is virtually invisible. And the person in such circumstances manifests spiritual bankruptcy, for the spirit of the century imposes to a modern man a skeptical attitude towards his own thinking, to make it receptive to the truths, derived from authoritative sources. The person cannot provide adequate resistance to these constant influences, moreover, according to A. Schweitzer, "falling to his lot financial difficulties affect his mental abilities in such a way that, in the end, he begins to consider himself insufficiently prepared to claim his own views" (Schweitzer, 1990, p. 330-331).

Some authors in the definition of mentality do not include individual characteristics. So, V. E. Semenov characterizes the mentality as "a historically formed grouped, long-termed state of mind, the unity of conscious and unconscious values, norms, attitudes in their cognitive, emotional and behavioral terms."(Semenov, 2000, p. 386)

The mentality seems to us one of the ways to preserve a person's integrity. It is important to remember that the phenomenon of mentality of personality plays an important role not only in the consciousness of the individual, but also his relationship with the human community, and also the system settings of the society as a whole. The peculiarity of the individual, appear to us as a man possessing the necessary minimum rights, advantages, and appropriate safeguards, as a unique individual (with even a minimum of that identity), is able to regulate, to restrict his behavior in various standards: legal, economic, technical, is that in itself it is opposed to the environment, surrounding it, as in essence the identity is autonomous, independent, and free in solutions. But at the same time the person belongs to the environment, as he makes choices, takes decisions and acts in the framework of the society, builds a behavior according to the standards established in this society, and is also limited by other individuals who are in same plane with its space.

In the literature there is a persistent idea that the Russian people and Russia as a whole are set in a rush, in a move to something otherworldly, to a different world. But if we start to find out what is necessary for Russia to realize its ideals, it turns out that it is necessary to be strong, powerful nation.

The uncertainty connected with the line East-West (mega level), and the lines of the reform, counter - reform (macro-level) puts a mark on the individual (micro-level).

Estimating the personal characteristics of the individual in such conditions, some scientists see inflated self-esteem of people, others vice versa, talk about low self-esteem of our citizens.

Historically, due to various reasons (of objective and subjective nature) in our worldview the political mentality aimed not at "l" and at "We" was developed. It is, on the one hand, an obstacle in the modernization reforms and on the other hand, the necessary protection in case of the collapse of the modernization projects.

The reality of this situation we face to this day, for thinking and acting "on orders from above", to live "under the order", has become a habit for millions of people, and "the habit of million is a terrible force". However, there are very difficult issue of personal choice, for "any villain, no matter how diabolical genius he is, even the party of possessed the prophets, are not able to force millions to self destruction, if they do not find within the mass consciousness the dark power, in tune with their own insanity" (Batygin, 1991, p. 266). In other words, within the mass consciousness there are mental structures, in the terminology of G. S. Batygin, "dark force", which should be consonant with the "order from 
above". If this harmony is not observed, then the authorities ' efforts on modernization will be ineffective, as "workforce" and the ultimate consumer of modernization projects are mass, i.e. the people, "the common people".

The orientation of the Russians on authoritarian methods of state political administration was facilitated by the fact that historically in Russia, and in Ancient Rus, the value of the person, the individual is very low. Until recently, Russia was a country where for a long time dominated the communal nature of life and human activity. This is largely objectively contributed to the devaluation of the values of the individual.

The formation of the personality positive attitude to the authoritarian system of power contributed to the system of Russian education, as the main type of interaction that is implemented today and at all levels of education in Russia, is interaction on the type of "teacher-student", which implies the unconditional subordination of the latter to the first.

And finally, the sympathy for the authoritarian system of power in personal preferences forms special attitude of our citizens to the authorities.

\section{Conclusion}

The allocation of mega-, macro - and micro-levels of influence of mentality on the processes of Russia's political modernization has rendered to vividly see this process and to differentiate it.

On the mega-level is such a feature of Russian political mentality, as the priority of stability before-oriented reforms. The detachment of citizens from participation in politics (because of desocialization) leads to a lack of understanding by citizens of the modernization efforts of the state and the reluctance to participate in them, which in its turn will block attempts to implement social changes. These mental traits, which were formed by the succession of generations throughout the centuries cannot be changed in the shortest possible terms.

At the macro level, the influence of mentality on the processes of political modernization is most pronounced in the traditions that are tied to the appropriate regional (ethno-national) mentality. Due to the fact that mental characteristics are formed at the stage of primary socialization, and then are broadcasted in the system of culture through cultural codes, regional (ethno-national) mentality is firm and is little subjected to external influences, and in cases of civilizational faults can be the guarantor of stability in society.

At the micro-level the impact of mentality on political modernization is characterized by the fact that the individual mentality sets cognitive and activity-based algorithms, which are not realized by the person himself, but, nevertheless, form his thoughts and feelings in a quite certain way. Namely at the micro-level is formed the "Russian spirit", which is supported by acts of interpersonal communication, which make exceptional originality in individual mentality.

We note that at all three levels the mentality has grandiose resistance to outside influences, to social impacts, to the most severe political and economic transformations and it is imperative to keep in mind when making a choice of the vector of Russia's political modernization.

\section{References}

Covetov, V.F. (2007). Integrative potential of the Russian mentality. Dis.Cand.philosophy. of Sciences, Nizhny Novgorod. pp. 4.

Khanakhu, R.A. (1997). Traditional culture of the North Caucasus: the challenges of the time. Maykop. pp. 66.

Andreeva, E.A. (2005). On the concept of mental/mentality in modern Russia //http://sib-subethnos.narod.ru/p2005/andreeval.htm

Petrushenko, T.K. (2005). Russian mentality in the midst of an evolving society // Modern problems of Russian mentality. Materials of allRussian scientific-practical conference 24-25 November 2005/ Ed.ed. V. E. Semenov - SPB. 2005. pp. 75-76

Simonyan, R.Kh. (2012). From national government to regional associations // Questions of philosophy. №3.

Modern don Cossacks (political, social, economic profile) 1992. Rostov-on-Don. pp. 16.

Sysoeva, O.N. (2007) The role of the Cossack societies in the system of local self-government (sociological analysis). Dis... candidate. doctor. Sciences. - Novocherkassk.

Zakharova, E.M. (2005). Formation of civic values in the family // Modern problems of Russian mentality. Materials of all-Russian scientific-practical conference 24-25 November 2005. IANS. Ed. V. E. Semenov. - SPb. pp. 124-125.

Schweitzer, A. (1990). Reverence for life as the basis of ethical world - and reassurance // Global problems and human values. pp. 330 331.

Batygin, G.S. (1991). Metamorphosis of utopian consciousness // Quintessence. M. pp. 266.

Semenov, V.E. (2000). The typology of the Russian mentality and the inherent ideology of Russia // Social psychology in the works of domestic psychologists. Reader. SPb. pp. 486.

Efirov, C.A. (1989). Social narcissism (mass blindness lasting for decades) // human dimension /edited and with a Pref. A.G. Vishnevsky. M. pp. 26, 48.

Popova, I.M. (2000). Everyday ideology. How they live, change and disappear. Kiev. pp. 31-33. 